\title{
Política de inclusión social en el gobierno de Chávez: una mirada a su proceso*
}

\author{
Rodríguez Colmenares, Isabel**
}

\begin{abstract}
Resumen
La implantación de la política pública social comporta una serie de obstáculos de diversos tipos; máxime cuando su eje articulador es la inclusión. En esta investigación analíticamente, se registran cinco de ellos, que cobran fuerza en la actual ejecución. La investigación es descriptiva, soportada en una revisión hemero-bibliográfica y arqueo de fuentes oficiales. El supuesto concibe la existencia de trabas que dificultan su desempeño, provenientes de: a) el estilo de negociación política; b) las características del sistema democrático y la constitución del sistema político; c) la lógica preexistente en el aparato público; d) la capacidad de respuesta de los actores sociales y del uso de la información y; e) la resistencia al cambio. Se concluye que para atender el estudio de la política, como sus alcances y las limitaciones de su quehacer, hay que considerarlos en el contexto histórico en el cual esa política se este adelantando.
\end{abstract}

Palabras clave: Política social, gobierno de Chávez, inclusión social, Venezuela.

\section{Social Inclusion Policy in the Chavez Government: A Look at its Process}

\section{Abstract}

The implantation of public social policy involves a series of obstacles of diverse types, especially when its principle axis is inclusion. This analytical research records five of these obstacles that are getting stronger in the current exercise. The research is descriptive, supported by a review of books, periodicals and official sources. The supposition conceives the existence of hindrances that

\section{Recibido: 31-01-12. Aceptado: 15-10-12}

* Este trabajo forma parte de los resultados del proyecto de investigación: "política pública social en Venezuela: alcances y limitaciones durante el período 1999-2009", registrado ante el Consejo de Desarrollo Científico y Humanístico de la Universidad del Zulia.

** Socióloga. Magister en Ciencia Política. Investigadora del Centro de Estudios de la Empresa de la Facultad de Ciencias Económicas y Sociales de la Universidad del Zulia, e-mail: isarodricol@hotmail.com 
make performance difficult, stemming from: a) the political negotiation style; b) characteristics of the democratic system and the constitution of the political system; d) pre-existing logic in the public apparatus; d) the response capacity of social actors and the use of information and; e) resistance to change. Conclusions are that to adequately study policy, its scope and the limitations of its activities, it should be considered in the historical context within which that policy is set forth.

Keywords: Social policy, Chavez government, social inclusion, Venezuela.

\section{Introducción}

A partir del año 2000 se viene planteando un proceso de transformaciones significativas en materia de política social en Venezuela; que comienza a concretarse a partir de 2003, cuando tiene lugar la implantación de las misiones como ejes ordenadores de ella. Dichos cambios y transformaciones no son un hecho aislado, son característicos de nuestra realidad. Bemeguy et al. (2009) sostienen que la principal característica del momento histórico actual es la complejidad de las "cuestiones"1 que afectan a las sociedades, y el grado de incertidumbre que despierta el futuro, provocado por la obsolescencia de los conceptos y prácticas tradicionales, en casi todas las dimensiones de la vida.

De allí que, la búsqueda de soluciones alternativas de políticas públicas so- ciales que irrumpan en contra de los parámetros convencionales, pretendiendo alterar la lógica de los usos institucionales y las concepciones tradicionales, formen parte de la nueva acción del gobierno y de la conducta del Estado, con miras a ubicar la inclusión social como eje articulador de la política pública social, como resulta ser en el caso venezolano.

A pesar de no haber un único uso del término "política pública" ${ }^{2}$ social y sobre los objetivos que con ella se persiguen, interesa contrastar, en un primer momento, las diferencias que se han venido registrando entre la forma y manera como en el pasado reciente se definió la política pública social (pps) y lo que en dicha materia se ha generado a partir de la promulgación de la Constitución de la República Bolivariana de Venezuela (1999) en relación al contenido formal que la

1 Con el empleo del término "cuestión social" se hace referencia a la existencia de conflictos sociales develados por organizaciones sindicales y políticas de los trabajadores, que reclaman cambios revolucionarios. A finales del siglo XX, la exclusión aparece como una nueva cuestión social, que se expresa en diversos problemas entre los que destacan: desempleo, precarización laboral, incremento de la pobreza, desigualdad y desmejoras en las condiciones de vida de la población (Isuani, 2007).

2 Este término, si se considera su tardía incorporación en el ámbito de las ciencias sociales y políticas (década del cincuenta) ha adquirido una poderosa influencia. El ritmo de su especialización ha dado origen a un sinnúmero de propuestas de estudio vigorizando la ciencia administrativa, las ciencias políticas y las sociológicas. Empero, la visión sobre política pública social no ha gozado de tan amplio y generoso desarrollo. Corresponde a América Latina recuperar a plenitud los esfuerzos teóricos y empíricos en esta materia dado que en esta geopolítica se plantean algunos de los retos más acuciantes para resolver los problemas sobre la exclusión social. 
Política de inclusión social en el gobierno de Chávez: una mirada a su proceso Rodríguez Colmenares, Isabel

contiene. Se considera que, con su aprobación se comienza a dibujar un ejercicio político encaminado a redefinir la relación Estado-Sociedad bajo una geometría de poder que ha venido dando origen al despliegue de una racionalidad política-institucional distinta.

Tal como sostiene Gutiérrez (2011) cuando afirma que hay que considerar otras dimensiones como la cultural, la política, la psicológica y la ética. Lo que supone la reconfiguración de los esquemas interpretativos anteriormente utilizados para conocer y simbolizar la realidad. O como sostiene Arellano (1996) al plantear una revisión del instrumental técnico, el cual aporta algunas inferencias pero no constituye el eje central de la formulación de la política social y de su implementación.

Para alcanzar los objetivos propuestos en la investigación se acude a la revisión, sistematización y análisis teórico y de contenido de diversas fuentes oficiales; así como, al arqueo biblio-hemerográfico. El horizonte temporal comprende los años de 1999 hasta el 2010, intentando efectuar la identificación de algunos nudos críticos, considerando los desafíos que representa impulsar una propuesta de esta naturaleza, dada la lógica de funcionamiento que ha prevalecido por parte del Estado en materia de política social; y el cómo se ha asumido el análisis de esta bajo los parámetros teóricos tradicionales.

\section{Una mirada teórico-histórica}

Los años noventa fueron testigo de una profunda revisión de los enfoques teóricos, de las prácticas metodológicas y de los constructos de política pública que se diseñaron para acometer o darle respuesta a la multiplicidad de problemas sociales, políticos y económicos que se vivieron tanto en Venezuela como en gran parte de América Latina.

Uno de ellos fue el de los modelos de desarrollo en relación a la manera de concebirlos y sobre las políticas que había que adelantar para alcanzar los objetivos previstos. En esta dirección, en el afloramiento de la discusión los organismos internacionales asumieron una posición autocrítica con respecto a su concepción del desarrollo. Tal es el caso de la visión del Banco Mundial, evidenciada en el Informe sobre el Desarrollo Mundial 1999-2000, En el Umbral del Siglo XXI (Banco Mundial, 2000), donde presenta el Marco Integral del Desarrollo, en el cual incorpora distintas dimensiones a la discusión (estructurales, físicas, humanas y sectoriales) y, supone la superación de la visión economicista del desarrollo que proclamó en décadas anteriores.

La referencia a esta institución constituye un significativo dato debido al impacto que ella tiene en América Latina. También es de destacar la trayectoria seguida por la Comisión Económica para América Latina y el Caribe (CEPAL), quien a comienzos de la década del noventa, hace el planteamiento en torno a la Transformación Productiva con Equidad (Cepal, 1990).

Igualmente, desde esa misma institucionalidad internacional, el Programa de las Naciones Unidas para el Desarrollo (PNUD) hace su aporte con respecto al Desarrollo Humano y; la Comisión Mundial de Medio Ambiente y Desarrollo con el Desarrollo Sustentable. Estas representaciones del desarrollo superan la 
perspectiva economicista y lineal que se tenía del mismo, puesto que parten de la complejidad e integralidad inherente a él, incorporando elementos como lo local, lo humano, lo ambiental. Estos planteamientos tienen profundas implicaciones en la manera de entender y operacionalizar la política social, establecer su vinculación con la política económica y el rol del Estado, entre otros efectos.

Otro tema central de revisión y motivación transcendente en la reestructuración paradigmática, que tuvo lugar en la década de los noventa, es la pobreza. Según Barba (2009), la pobreza se ha constituido en un tema central en la agenda política, dado sus enormes dimensiones en términos demográficos; así como, las implicaciones sociales y políticas que conlleva su incremento para la legitimación de las acciones de gobierno y; adicionalmente, por los temores sociales que despierta su aumento para el Estado y la sociedad.

En particular en la década del noventa asistimos a una diversificación de los argumentos críticos, las razones sobre su origen, el mantenimiento del fenó- meno, a pesar de los distintos esfuerzos hechos para controlarla; $y$, lo que resulta ser más preocupante es el surgimiento de los "nuevos pobres"3. Aún cuando esta categoría ha sido reelaborada en América Latina para hacer referencia al empobrecimiento de grandes sectores de la clase media considerando lo extenso de la crisis, la pérdida del ingreso, la cobertura de la seguridad social (Barba, 2009), la privatización y la tercerización promovidos por la aplicación del enfoque neoliberal. Así como también, la insuficiencia en la consideración de derechos sociales más diversos, lo que generó efectos contrarios a la búsqueda de políticas más cónsona con la inclusión social.

Evidentemente, la inclusión social no constituyó una prioridad en las décadas del sesenta, setenta y ochenta. La preocupación por la inclusión social, en términos de la perspectiva de los derechos sociales, hace su aparición con motivo de la revisión crítica adelantada producto de la crisis y de los erráticos logros en materia de erradicación de la pobreza y el mejoramiento de las condiciones de vida de la población en toda aquella franja

3 Término empleado por varios autores para referirse a la situación de pobreza de la población por la transición demográfica que se ha registrado en América Latina a partir de 1990; también por el incremento del desempleo, la inflación, la reducción drástica de las corrientes financieras y la caída de las exportaciones que marcaron el desarrollo de la crisis afectando las economías de la región cuyas condiciones eran mejores que las que se han venido produciendo en estos últimos diez años. El concepto de "nueva pobreza" tiene su origen en la teoría sociológica, él hace alusión a las características particulares que identifican a grupos empobrecidos en comparación con aquellos pobres que ya existían en cada país. En Europa occidental este concepto fue adoptado en la década del ochenta cuando se suscitó el interés por la reflexión de los nuevos problemas sociales que vinieron a tener lugar con el inusitado incremento del desempleo y la pobreza. La primera publicación en la cual aparece el término es alemana, en 1984, en Balser Nakielski et al. (1984). Ver al respecto el trabajo completo de Kesslen y Di Virgilio (2008). 
en que se encuentran ubicados los llamados países del "tercer mundo ${ }^{4 "}$ y dependientes que se encuentran en la órbita del capitalismo periférico ${ }^{5}$.

Considerando el abanico de opciones que presentan los estudios que han sido elaborados en la década de los años noventa sobre América Latina, los autores han llegado al convencimiento, por fin, del reconocimiento de que "lo social debe estar en el centro y no en la periferia de la discusión sobre el desarrollo". Esta tendencia ha conducido a priorizar el desarrollo social como componente fundamental del desarrollo. Esto ha desembocado en la propuesta de agendas alternativas de política social (Barba, 2009), que representan diversas propuestas en las cuales las experiencias, a pesar del poco tiempo que llevan, han logrado alcanzar diferentes efectos.

La finalidad de las políticas sociales se amplía y adquiere una nueva direccionalidad que conduce a una inédita orientación paradigmática, que prescriptivamente no sólo atienden a una "intervención deliberada del Estado para redistribuir recursos a sus ciudadanos con el propósito de alcanzar un objetivo de bienestar" (Baldock et al., citado por Delgado, 2002), sino que contemplan otros pro- pósitos más abarcantes y trascendentes dirigidos a reconocer y satisfacer otros derechos sociales, económicos y políticos de los ciudadanos.

En esta dirección, se reconoce que la política social que se adelanta en la actualidad, en Venezuela, comprende una doble dinámica tal como expone Delgado (2002); las reformas enmarcadas en la perspectiva de los derechos y la justicia responden a esa doble dinámica: La primera, orientada a materializar efectivamente los derechos del bienestar, en procura de elevar la calidad de vida en una triple vertiente: construir una ciudadanía activa, una mejor democracia y disminuir las desigualdades. La segunda, dirigida a reforzar las bases institucionales bajo la generación de reglas de juego que estimulen el ejercicio de los derechos civiles y políticos sobre todo teniendo presente prioritariamente a los excluidos de la toma de decisiones.

En efecto, desde mediados de los noventa, por las limitaciones de las políticas sociales aplicadas, surge como alternativa el enfoque de derechos en las políticas y estrategias de desarrollo. De manera que, los derechos humanos sirven de marco para sustentar las políticas de desarrollo. Esta posición implica el compromiso de los Estados de reco-

4 El término Tercer Mundo acuñado por el demógrafo francés Alfred Sauvy (Giddens, 2000:93) refiere a las sociedades que no se han industrializado, en contraste con las del Primer Mundo ya industrializadas y las del Segundo Mundo bajo régimen socialista.

5 Capitalismo periférico, término empleado y desarrollado teóricamente por los tercermundistas como amir Amin, Pier Jallet, para significar en la lógica de la expansión capitalista, la relación que se establecia entre los países del centro y los otros que erosionaban la capacidad de desarrollo independiente de ellos. Por lo que la pobreza y la distribución desigual de los ingresos no son efectos negativos causados por circunstancias específicas o políticas erróneas, sino resultado de la propia lógica del sistema (Amin, 1999). 
nocer y aplicar convenimientos del derecho internacional sobre los derechos humanos (cívicos, políticos, sociales, ambientales y culturales). Esto conlleva a la injerencia del Estado en los asuntos del desarrollo, en este caso, en la política social, luego de su retrotraimiento ante las posiciones mercadocéntricas que obligaron a su retiro.

Sobre el tema, Arriagada (2006) habla de la tercera generación de políticas sociales que emerge del reconocimiento de los derechos ciudadanos y amerita la reestructuración de las funciones del Estado, la reorientación de las políticas públicas y la participación ciudadana. A este enfoque también se le han realizado críticas, entre las que destacan: la ambigüedad en el tratamiento del contenido de las obligaciones de los derechos económicos, sociales y políticos; la viabilidad sobre su exigibilidad, al igual que de los cívicos y políticos. Sobresale entre otros rasgos específicos su carácter rígido con respecto al aporte del contenido de las políticas, mas no a su marco de aplicación (Abramovich, 2006).

Según Lahera (2004), las políticas públicas se constituyen en un factor común de la política y, simultáneamente, de las decisiones que asume el gobierno y de la confrontación positiva o negativa que admite la oposición. En particular, la política pública social se convierte en un foco de tensión, no solamente, para el gobierno sino de éste con respecto a los actores que encarnan la oposición y/o otros actores presentes en la estructura burocrática del aparato de Estado.

En la actual coyuntura venezolana es donde mejor se aprecian o evidencian esas tensiones, dado la multiplicidad de actores sociales y políticos que influyen, en general, en los procesos políticos, en las decisiones, la ejecución o control de las actividades públicas que conlleva la formulación y aplicación de la política social, ya que ellas no son de la exclusiva competencia de los expertos (Fleury, 2002); sino que son la resultante de una determinada visión de cómo manejar los asuntos públicos por parte del quehacer del gobierno donde cristaliza una selección de temas y objetivos del programa de gobierno (Lahera, 2004) y, más aún, tratándose de una etapa histórica de transición donde se está impulsando un nuevo modelo de sociedad, así la aparición de conflictos y tensiones afloran con mayor frecuencia que cuando se trata de instaurar políticas de funcionamiento del sistema, que son cónsonas con la racionalidad ya constituida.

Por tanto, el estudio de las políticas públicas en el transcurso de 13 años del gobierno de Chávez tiene que ser examinado considerando varios aspectos que se describen a continuación:

1. La complejidad que resulta del establecimiento de nuevas políticas públicas por parte de un gobierno encaminado a redefinir la relación EstadoSociedad, que ha venido dando origen al despliegue de una racionalidad política-institucional distinta, cuyas características principales se expresan en: a) revalorización del rol del Estado, mediante la reorganización del aparato público; b) instauración de mecanismos de participación amparados por estatutos normativos constitucionales y leyes específicas; c) primacía del término inclusión social como eje de las directrices de la 
política social; d) incorporación del reconocimiento de las ausencias y/u omisiones en la política social incorporando la "deuda social"; y e) promoción de la responsabilidad social a todos los niveles en el ejercicio tanto de lo público como de lo privado; entre otros rasgos distintivos.

2. La reorientación de la política pública distanciándose de lo planteado y aceptado por la propuesta del Consenso de Washington; aspecto este que será desarrollado más adelante por las implicaciones que de él devienen.

3. La superación del rumbo de la propuesta de corte neoliberal, que había entrado a enquistarse en la realidad venezolana a partir de la década del ochenta, dado que para aquellos años "Venezuela se había convertido en una sociedad anómica, sin rumbo y sin proyecto político de futuro en el marco de unos precios del petróleo que no permitían financiar la crisis fiscal y producían un creciente endeudamiento interno y externo y una cada vez más inaceptable exclusión social" (Díaz Polanco y Borges, 2010: 39).

4. Sustentar el compromiso ético. Afrontar el análisis de la política de inclusión social no sólo representa acompañar los desafíos que ella ha tenido que soportar en su proceso de formulación e implantación, sino responder al deber ético que supone el análisis de políticas públicas. Merino (2008: 7) sostiene que, "desprovistos de todo contenido ético, el enfoque de la política pública no sólo puede perder profundidad, sino que minaría incluso su eficacia”. Este autor enfatiza que es absolutamente necesario incorporar el aspecto ético al análisis que se efectúe de las políticas públicas porque de hecho siempre hay un involucramiento de los valores, de las posturas, de los compromisos ideológicos y políticos. La neutralidad no es la opción. La rigurosidad se alcanza con la solvencia de los argumentos y las demostraciones empíricas y teóricas. Se asumen los retos y se afrontan las refutaciones: sobre todo cuando se comparte que tanto el proceso de formulación como en el de su ejecución de una política pública no consiste sólo en la "repetición mecánica de un conjunto de procedimientos establecidos (por muy perfectos que estos lleguen a ser diseñados), sino que supone también capacidad de adaptación y compromiso con los valores previamente asumidos" (Merino, 2008: 23).

\section{Desafíos de la política de inclusión social}

El gobierno de Hugo Chávez Frías ha formulado una propuesta de política social orientada a alcanzar la equidad, la inclusión social y el bienestar; fortaleciendo el rol del Estado, creando una serie de mecanismos de participación social que han puesto en tensión las dos concepciones más sobresalientes de política social, 1) la entiende como responsabilidad del Estado; y, 2) estima que el Estado debe limitar su actuación en política social. Esta última se encuentra inspirada en el enfoque neoliberal que adquirió auge desde mediados de la década de los ochenta, cuando ya la crisis se había instalado y era irreversible. Tanto los detractores como los afectos al gobierno reconocen 
que en Venezuela se viene registrando una transformación significativa en la implantación de la política social, independientemente de las turbulencias, incertidumbres, complejidades y tensiones que dicho proceso ha suscitado.

Cuando se indica a contracorriente que se esta considerando de manera significante lo formulado por el Consenso de Washington, que vino a ser la resultante del informe presentado por Jonh Williamson titulado "Lo que Washington quiere decir por reforma de la política" en el cual se definen las diez recomendaciones de políticas económicas que debían ser adoptadas por los países de América Latina (Moreno Brid, 2004).

Estas directrices vinieron a sustituir al estructuralismo cepalino como marco de referencia convencional para abordar la cuestión social y; que en opinión de Barba (2009), este cambio significó el fin de la tentativa regional de lograr una modernización de carácter regional y terminó por derrumbar la coalición distributiva que le dió soporte al proceso de industrialización. De allí el significado histórico que tuvo la aplicación de dicho consenso, porque motivó el surgimiento de una nueva hegemonía en donde aparecen los actores transnacionales integrados a funcionarios gubernamentales y agencias financieras; así como, asesores e inversionistas internacionales que se articularon en torno al discurso socioeconómico e ideológico que persiguió hacer relevante la construcción de "sociedades de libre mercado abiertas a los flujos económicos globales" (Barba, 2009).

Entonces, no sólo la década del ochenta fue bautizada como la "Década Perdida", por los propios representantes de la CEPAL, sino que la del noventa adquirió también una connotación catastrófica y pesimista al no alcanzar los objetivos que se plantearon los representantes de los organismos internacionales, quienes la definieron como la "era del vacío".

De tal manera que, los años de la década del ochenta $y$, particularmente, los del noventa, son indicativos o se convierten en referente obligado para, retrospectivamente, apreciar las diferencias existentes; así como, poder distinguir comparativamente, en el tiempo, lo que representó la política social en aquellos años y lo que es la política pública social en la actualidad.

En la diversidad de estudios que se adelantaron en aquellos años, siempre se insistió en el escaso impacto que alcanzó la implantación de los programas. Cuando, por ejemplo, se quiso justificar la focalización brotaron todos los problemas que devenían de la aplicación de las políticas universalistas para enfatizar que era necesario introducir políticas sociales compensatorias para corregir simultáneamente, los problemas heredados del paradigma universalista ${ }^{6}$.

6 Según Ocampo (2008) el paradigma universalista ha sido objeto de dos críticas: una va dirigida a indicar que para adelantar las políticas se requiere la disponibilidad de muchos recursos y, en segundo lugar, frente a presupuestos escasos se termina ejecutando una mala focalización de los recursos. 
Política de inclusión social en el gobierno de Chávez: una mirada a su proceso Rodríguez Colmenares, Isabel

Para el especifico caso venezolano se considera que los años de 1980 constituyeron la "década eslabón", en donde decantaron, fraguaron y amalgamaron los efectos negativos de los años del setenta, dado el comportamiento político de los dos partidos que hasta ese entonces aparecian como opción, social cristianismo y social democracia (COPEI y AD) ${ }^{7}$. La concepción ideológica, política y de racionalidad con la que ellos actuaron se fue fundiendo con la del Estado; imponiéndose su hegemonía sobre toda la sociedad, sin que entre ellos existiera una diferenciación sustantiva que permita catalogarlos como modelos políticos con doctrinas, ideologías y modos de actuación diametralmente opuestos; por lo que se puede afirmar que en cuanto a modo de actuación tanto la concepción de AD como la de COPEI se comportaron con una similar racionalidad construyendo un estilo que tuvo continuidad en el tiempo y que influyó en todo el sistema político.

La valoración negativa de ambos en el ejercicio de gobierno y de algunas políticas adelantadas por ellos no difirieron mucho en cuanto a resultados, por cuanto los cuestionamientos a que dieron lugar en su momento y sus efectos en el tiempo sobre la década del noventa adquirieron una relevancia histórica incuestionable. Esto condujo a evidenciar que entre la política económica y la política social se vino presentando un desencuentro. En la generalidad del trayecto histórico que va desde la instauración de la democracia, el modelo de desarrollo que se adoptó se caracterizó por una activa y profusa intervención del Estado, como ente regulador y promotor de la actividad económica (Vivancos y España, 1993).

Sin descuidar reconocer, que se destinaron importantes recursos a lo social, que el proyecto político populista requería para su afianciamiento, sin tomar mucho en consideración si ese caudal de recursos eran o no adecuadamente empleados, si los programas sociales eran eficientes y si contribuían o no al logro de la equidad social.

La política social desarrollada a la luz del tamiz histórico como resultado tuvo un impacto condicionante en el desarrollo de conductas sociales poco proactivas y de estímulo al surgimiento de liderazgos responsables en la comunidad. Por lo que para Vivancos y España (1993), resultó ser un problema históricamente significativo, el paternalismo estatal, el clientelismo partidista y la conjunción de intereses frente al Estado; adicionando, en consideración de nosotros, la dispersión del gasto social sin la suficiente evaluación de los programas.

De tal suerte, se dieron un conjunto de condiciones que estimularon la cristalización, en la práctica, tanto en el aparato público como en la sociedad en general, la falta de responsabilidad, honestidad y valoración social pertinente sobre los beneficios sociales "conquistados" y el componente ético con respecto al uso de los

7 Este período corresponde a los gobiernos de Luis Herrera Campins (1979-1983) y Jaime Lusinchi (1984-1989), pertenecientes a los partidos COPEI y AD, respectivamente (Guevara, 1989). 
recursos destinados para satisfacer las demandas sociales.

A continuación se presentan las características más significativas que entraban la realización de una política social de inclusión en un contexto de tensiones políticas, que afectan el desempeño institucional, y cuando algunos autores la relacionan con un profundo debilitamiento de la base de la institucionalidad, de la integración, de la cohesión social y política de los venezolanos" (D'Elia y Maingon, 2010: 365).

En contraposición a lo que estas autoras sostienen, ese debilitamiento ya existía. En esta nueva etapa histórica el propósito es crear una nueva institucionalidad. La anterior, producto de acuerdos político-partidistas, generó una cohesión social artificial articulada sobre unos valores que poco contribuyeron a crear un sentido de responsabilidad social y política en la administración de los recursos públicos, proclive a la continuidad administrativa, al cumplimiento de los planes, programas y actividades planteadas en la política pública social. Sin tampoco crear mecanismos legales suficientes para efectuar un adecuado seguimiento y determinación de sanciones.

\section{Principales características del desarrollo de una política social de inclusión en Venezuela}

Siempre, en todo análisis que verse sobre los cambios ocurridos por medio de la comparación de lo que fue y lo que se introduce para superar lo existente, hay que tratar de traspasar las nieblas que enturbian los recuerdos de aquellos que establecen un divorcio con los aspectos negativos de esos acontecimientos, por estar adheridos a una ideología conservadora que intenta recurrir al olvido como una manera de diluir las ataduras políticas o las responsabilidades con respecto a las políticas sociales formuladas y ejecutadas anteriormente.

En esta dirección temporal, en el centro del debate, aparece la contrastación conceptual, dado que las principales orientaciones doctrinarias de la política no se construyen en el vacio sino que son la resultante de concepciones que emergen, por así decirlo, por detrás, y que se convierten en el soporte teórico-filosófico doctrinario. De aquí que la contrastación analítica de los conceptos, de los postulados sobre los cuales se levanta el andamiaje de la política pública social no se encuentra desprovisto de ese arsenal teóricoconceptual. De allí proviene buena parte del constructo de la "racionalidad" con que van luego, en la práctica, a aparecer los fines que persiguen, las orientaciones ideológicas, la sustentabilidad del marco normativo-jurídico y la construcción del aparataje administrativo a partir del cual se desplegará la acción concreta de los programas que son la objetivación axiológica y pragmática de la política.

Tomando prestadas algunas ideas de Lahera (2004) se tiene que, si bien el diseño formal de las más diversas políticas públicas requiere del Poder Legislativo, por ser éste el espacio donde se concentran las negociaciones y acuerdos, (Asamblea Nacional) y donde, a la vez, son aprobadas, en definitiva, también responden, al juego de intereses que expresan -abierta o veladamente- los actores políticos, los burócratas, las élites, las 
Política de inclusión social en el gobierno de Chávez: una mirada a su proceso Rodríguez Colmenares, Isabel

organizaciones sociales, el propio gobierno y las ONG's, entre otras organizaciones con capacidad para ejercer presión en los asuntos públicos.

De acuerdo al análisis que se ha venido desarrollando han sido identificados cinco características que se esbozan a continuación:

\subsection{Las características e influencia del estilo de negociación política que surgió, y que todavía mantiene cierta vigencia, a raíz del Pacto de Punto Fijo}

En el contexto de la democracia representativa en Venezuela se impuso un estilo de negociación, en donde, en última instancia, prevaleció el sistema de "las coaliciones", pues privan más los intereses de los grupos políticos que lograron imponer su alternativa; independientemente del impacto que ellas pudieron haber tenido. Según Lahera (2004), en muchos casos se "negocia" más no tanto por la virtud de una política sino en atención al hecho de no quedarse afuera de ciertos privilegios y cuotas de poder.

Esto resulta ser muy poco beneficioso para los grupos políticos que no participaban de este juego, pues podrían ver disminuidas sus cuotas de poder y explica lo que significaron los largos períodos de espera para que una ley fuera aprobada, no interesaba sopesar el beneficio para los sectores sociales específicos hacia los cuales iba dirigida la política sino qué grupo político podría resultar perjudicado. Un ejemplo donde se evidencia esa lógica es lo que ocurrió con la Ley Orgánica del Sistema Nacional de Salud, Gaceta Oficial No.
33.745, de fecha 23-06-1987, que demoró ocho años en ser aprobada para luego no ser aplicada.

Claro está que otras leyes son aprobadas en menor tiempo. Esto ocurre cuando los actores políticos a pesar de encarnar intereses contrapuestos perciben que pueden alcanzar beneficios en el reacomodo del juego político; este fue el caso de la descentralización, ella no sólo se consideró como una idea fuerza de las reformas "sociales" lanzadas como solución al centralismo sino que permitió un auge de los liderazgos locales y una expansión de las cuotas de poder vía la dimensión territorial de las políticas públicas. Tal como ocurrió con la Ley Orgánica de Descentralización, Delimitación y Transferencias de Competencias al Poder Público fue aprobada el 28 de Diciembre de 1989 (Gaceta Oficial No. 4.153, Extraordinaria) y según respondió a una coalición de fuerzas sociales sin precedentes, logró desatar a su favor una campaña más dinámica y efectiva centrada en la opción de la elección nominal de las autoridades locales y regionales (De la Cruz, 1992).

No siempre la formación o formulación de una política es el resultado de la influencia ejercida por organizaciones sociales, políticas y económicas que ejercen presión, mediante un proceso por medio del cual un problema, una necesidad u objetivo, se conoce, analiza y se trata de construir una solución mediante el diseño de una política que se presenta, como un anteproyecto de ley ante, el Congreso Nacional, instancia legislativa que existió hasta su sustitución por la Asamblea Nacional, luego de ser aprobada en la Constitución de 1999. 
En el caso venezolano esta no fue la experiencia histórica que tuvo durante los dos primeros gobiernos de Acción Democrática que van de 1959-1969, el presidente $y$ fracciones parlamentarias de este partido fueron los que introdujeron casi todas las leyes sobretodo las de tipo económico. Durante el gobierno de Copei (1969-1974), el propio presidente fue el que introdujo casi todos los anteproyectos de Ley ante el Congreso. En el lapso que va de 1959 a 1974, los partidos de oposición solo introdujeron el $8 \%$ y los Comités el $4 \%$. Por los que estos datos son reveladores de la fuerte iniciativa que emanaba del ejecutivo (Presidente) en el planteamiento de asuntos públicos y su influencia en la elaboración de políticas (Gil Yepez, 1978).

Esto parece constituir una tradición que se desprende desde mucho tiempo atrás y que con la instauración de la democracia a partir de 1958 en adelante ha permanecido con escasas variaciones $y$ que se mantienen hasta la actualidad, porque la política pública social desde 1999 en adelante ha continuado con esa tradición presidencialista, ahora en los espacios de la Asamblea Nacional, porque la mayoría de las políticas sociales han sido el producto de la adaptación de lo formulado en las propuestas presentadas por el ejecutivo.

\subsection{Las características propias del sistema democrático y la constitución del sistema político}

De la manera como se ha venido funcionando, se registra la dinámica de relaciones entre el modelo político democrático y el sentido o concepción de la democracia, la cual ha resultado ser desfa- vorable, porque han surgido una serie de obstáculos.

Para Pickles (citado por López, 1998), el término democracia puede ser empleado para designar una variada gama de sistemas políticos; así como, a las formas de interpretar la democracia, entre otras, la democracia liberal, socialismo democrático, la liberal norteamericana, parlamentaria, representativa, la de corte neoliberal y la participativa.

De tal manera que las variantes sobre las democracias participativas han encontrado diversas posibilidades mediante la creación de estímulos que permiten el acercamiento, cada vez, más fluido y directo para que el sujeto acceda al proceso de toma de decisiones para que resulte beneficiado al alcanzar sus objetivos.

Sin embargo, existen algunos impedimentos que imposibilitan el desarrollo de la democracia participativa. Se sostiene que la "comunidad", así en genérico, puede influir políticamente en la determinación de las políticas públicas, de manera más continua que mediante los partidos políticos y las elecciones (Lahera, 2004). Pero se advierte que hay una dimensión que impone límites temporales y que la "sociedad civil" no cuenta con el tiempo necesario para que los individuos "formen grandes asociaciones voluntarias para fomentar temas de interés público, a menos que existan condiciones especiales para ello" (Lahera, 2004: 17).

El gobierno actual venezolano ha puesto de manifiesto una concepción diferente de la democracia que no se rige por la ortodoxia del paradigma de la "Democracia Representativa", donde los par- 
Política de inclusión social en el gobierno de Chávez: una mirada a su proceso Rodríguez Colmenares, Isabel

tidos políticos se adjudicaron progresivamente la representación de las mayorías y monopolizaron la toma de decisiones tanto a nivel interno del partido sino también en el aparato público.

A diferencia de lo que acontecía en aquellos años, en el proceso actual se tiende a vertebrar el sistema político a partir de la participación de los grupos organizados existentes en la comunidad para que, desde allí, vayan surgiendo las respuestas a los problemas sociales. Esto es, se le reconoce a la gente, al sujeto, al individuo, a los grupos organizados, la capacidad de decidir los temas de la agenda pública por la base y esto representa un avance significativo por cuanto, como plantea Lahera (2000), las políticas públicas tienen su génesis en la capacidad que tiene una sociedad para definir su agenda pública.

Estos cambios han alterado la lógica de funcionamiento de la democracia en Venezuela y esto se ha traducido en un férreo enfrentamiento que ha obstaculizado el avance de la política social de inclusión. Sin embargo, se sostiene en primer lugar, que si bien no se ha concretado en toda su extensión y profundidad dicho proceso, si se reconocen algunas esferas o aristas en las cuales se advierten cambios bien significativos. El hecho de contemplar políticamente una concepción alternativa a la participación, diferente a la que se había venido registrando, y crear mecanismos orientados a abrir canales más ex- peditos para que ella se concrete, como por ejemplo, la creación de los consejos comunales (Córdova, 2012).

\subsection{Las características que provienen del funcionamiento institucional de la administración pública.}

Desde la década del ochenta se viene insistiendo en la pérdida de confianza en la capacidad de la administración pública para ejecutar las políticas. Uno de esos problemas está relacionado con la fragilidad institucional.

Al priorizar atender la deuda social, el actual gobierno buscó consolidar una estrategia que tendiera a satisfacer una triple necesidad política en el funcionamiento del Estado: a) cuestionar los tiempos y modos de funcionamiento del aparato estatal en la conducción de políticas públicas; b) satisfacer las urgentes demandas sociales postergadas durante mucho tiempo (D'Amario, 2009); y c) construir una nueva institucionalidad acorde con las exigencias del nuevo modelo de desarrollo y de sociedad.

La búsqueda de la construcción de una nueva institucionalidad acorde con las exigencias de la política social de inclusión ha devenido en un reto trascendente dado que ya desde un largo tiempo atrás este venía siendo cuestionado, no solamente por la colonización ejercida por los partidos políticos tradicionales $A D$ y $\mathrm{COPEI}^{8}$, sino por una serie de vicios

8 En torno al juicio valorativo sobre lo que representó AD y Copei tenemos lo siguiente: Para el caso de AD, el máximo llegó con el gobierno de Jaime Lusinchi (1984-1988), período en el cual 
que entraban su capacidad operativa como la excesiva burocratización, la duplicidad de funciones, la dispersión de programas y recursos que si bien, en gran medida, pueden ser imputados a la presencia del clientelismo que, con frecuencia, se asocian al ejercicio del control del poder, también hay que considerar que las políticas públicas suponen una afirmación valorativa engranadas a una determinada concepción de la política y de la manera como ella interpreta al Estado, con respecto al modelo de sociedad que se desea impulsar.

Para Merino (2008:19) "las políticas públicas en efecto, tienen un núcleo duro que se deriva de la teoría de entrada que se haya elegido y que se construye con la argumentación que sirvió para definir el problema que se quiere solucionar".

Por lo tanto, contar con una nueva institucionalidad no ha resultado ser una tarea fácil; todo lo contrario ha sido una tarea difícil de resolver dadas las tensiones y contradicciones que se registran al interior del aparato público; sin embargo, ha sido absolutamente necesario dado que la implantación exitosa de una políti- ca pública no consiste únicamente en la repetición mecánica de un conjunto de procedimientos previamente diseñados y establecidos sino que requiere, sobre manera, capacidad de adaptación y compromiso con los valores previamente asumidos (Merino, 2008:23), lo que supone de entrada un compromiso valorativo con las directrices estratégicas de la política formulada y cuyos lineamientos más generales se encuentran formalmente recogidos en la Constitución, de allí el carácter de complejidad que lleva implícito.

No debe olvidarse que en Venezuela la organización del sector público era, y en muchos casos pervive todavía, extremadamente frondosa, con un número exagerado de entes públicos e instituciones que desarrollan planes, programas, proyectos y acciones desarticuladas entre sí; advirtiéndose a la falta de coherencia entre políticas y estrategias. Esto pone al descubierto una ausencia de planificación que integre la instrumentación de programas nacionales, subnacionales y locales con una presencia de coordinación que permitiera establecer la secuencia de las distintas acciones a ser

la concentración y concepción de poder alcanzarían uno de los niveles mas altos en la historia del país; por ejemplo, Blanca lbañez, que se convirtió en su amante y su secretaria privada, decidía sobre los beneficiarios de los contratos de obras públicas, nombraba y destituía funcionarios, seleccionaba los ascensos a generales del ejercito de acuerdo a sus criterios de amiguismo y lealtad al presidente, además de que le fueron otorgadas condecoraciones como la Orden del Libertador, a manera de desagravio por no haberle otorgado el título de Primera Dama (Ball, 1992). Con respecto a Copei, se tiene como ejemplo el gobierno de Luis Herrera Campins (1979-1983), quien valiéndose del poder pautó muchos acuerdos en beneficios de negocios propios, como ocurrió con el nombramiento del Ministro de Hacienda, Dr. Arturo Sosa, quien fue el responsable directo del "desbarajuste espantoso en la administración de 380 empresas del Estado e Institutos Autónomos y, sueldos de de 1.2 millones de empleados públicos" (Ball, 1992:297); que entre otros problemas dejó como herencia la perdida de confianza en la economía y el "viernes negro", el 27 de febrero de 1983, con la devaluación del bolívar. 
Política de inclusión social en el gobierno de Chávez: una mirada a su proceso Rodríguez Colmenares, Isabel

desarrolladas; así como, la falta de continuidad administrativa y el adecuado enlazamiento entre lo formulado por los distintos planes nacionales, quinquenales, que fueron concebidos más como planes de gobierno y no como planes de Estado considerando un período prolongado.

Estos problemas han requerido ser superados con el planteamiento de las misiones, las cuales originariamente surgieron ad hoc desde el 2002 en adelante, pero que en la actualidad han ido adquiriendo una integración, todas direccionándose hacia consolidar la inclusión social (Alvarado, 2012).

\subsection{Insuficiencia de mecanismos de información y divulgación}

El desarrollo de la información, su potencialidad y su necesaria presencia para hacer llegar a los colectivos sociales lo qué se hace, cómo se hace, a quién va dirigida la acción de los programas y la importancia que reviste la participación en las políticas públicas alcanza, hoy por hoy, una centralidad indiscutible; que se expresa no solamente en la añeja relación entre saber y política, "que constituye un tema clásico del pensamiento político que suele suscitar polémicas y posiciones divergentes en las disciplinas sociales y humanas" (Moro, 2009:297), sino que cobra vigencia por los diversos tipos del impacto que devienen de la incidencia de la información en el comportamiento del individuo tanto en la sociedad como en el que se desempeña en cualquier organización privada o pública.

Según Scott Morton (1991, citado por Rodríguez, 2000: 245), las nuevas tecnologías de la información están ha- ciendo posible que se produzcan cambios, hasta hace muy poco impensables en las diferentes esferas de la administración pública, por ejemplo, en las formas habituales de efectuar el trabajo, en la coordinación (es posible superar la distancia, el tiempo y mantener actualizada la memoria organizacional); y en el trabajo general, que suscitan y proveen posibilidades impactantes. Requiriendo que existan equipos que sean capaces del diseño de los sistemas de información con expertos entrenados para que los decisores puedan hacer uso apropiado y oportuno de ellos.

En las empresas públicas en general y, en particular, en las organizaciones del Estado que desarrollan la política social ha sido una constante encontrar diversas fallas a este nivel, por ejemplo los datos no se encuentran disponibles, la metodología utilizada no guarda un patrón homogéneo, los criterios de registro cambian, y los informes, anuarios, memorias entre otras, donde son publicados o no son periódicos o responden a modificaciones que no permiten diseñar investigaciones secuenciales de tipo comparativo.

En este sentido, el diseño de un sistema de información de la política social no debe consistir única o exclusivamente en reunir o acumular datos sin establecer criterios de selección para determinar cuál es la información relevante a los fines de medir y evaluar la trayectoria de lo que se ha venido haciendo; así como poder identificar las fuentes claves de suministro de información para nutrir a la propia organización, así como, las que permitan el desarrollo de las campañas de divulgación dirigidas al público (Rodríguez, 2000). 
Por otro lado, hay que prestar atención a la cuestión pedagógica de la información, para que ella trascienda al plano de la comunicación, de manera que, los beneficiarios realmente puedan decodificar el mensaje y propendan a efectuar cambios conductuales que son los que van a propiciar modificaciones intersubjetivas en las pautas de valor, creación de confianza, aceptación de la diversidad y acompañamiento responsable con la finalidad de reconocer que el logro de los objetivos de las políticas públicas sociales, en este caso, de inclusión, requieren de este compromiso por parte de los sujetos a los cuales va dirigida.

Se considera que una de las principales fallas en las que se ha incurrido en la ejecución de la política social en el actual gobierno es en el proceso de su divulgación, en dos vertientes críticas: Una, la que se proyecta a través de los medios de comunicación masiva: radio, televisión, prensa; que ha sido construida más con una finalidad propagandística genérica donde se destaca más la forma típica del personalismo político del gobierno en general, que si bien se apoya en querer reivindicar a los sectores excluidos reconociendo la deuda social que el Estado tiene con ellos, que durante muchos años los condujeron a la situación de empobrecimiento que padecen, no da cuenta efectivamente sobre cómo se están invirtiendo los recursos y a quién está llegando y qué resultados se están teniendo en términos mas detallados y específicos. La otra vertiente, es que no se pone a disposición la información a todos aquellos interesados en conocerla. Pareciera existir un signo de desconfianza que bloquea esa posibilidad. Esto ha generado recelo y ha dado oportunidad para que aparezcan interpretaciones tergiversadas por parte de quienes adversan al gobierno, haciendo gala de las mas diversas conjeturas, desconociendo cualquier rasgo positivo sobre lo que se ha venido haciendo.

Sin embargo, estos problemas no son exclusivos del caso venezolano, Moro (2009) sostiene que suele ser clásico el cuestionamiento al escaso uso e impacto de la producción de información y conocimiento en la gestión pública, produciéndose escepticismo por parte de técnicos y profesionales, pertenecientes o no a los ámbitos de gestión y burócratas en general. Máxime cuando se trata de un cambio de modelo que afecta intereses de los propios técnicos y burócratas al interior del aparato público así como también a aquellos actores que expresan otros idearios políticos e ideológicos, por lo que se producen tensiones tanto al interior de la propia gestión como fuera de ella, que se ven reflejadas en el uso que se da a la información en el vaciamiento y procesamiento divulgativo a través de los medios de información.

\subsection{Resistencia al cambio}

Entre las características asociadas, consideradas que la resistencia al cambio parece ser una actitud muy atribuida por los psicólogos sociales y los antropólogos culturales vinculada a los patrones de las sociedades tradicionales muy poco penetradas por los cambios rápidos, las exigencias de la modernidad y la adaptación a situaciones nuevas y diversas. La administración pública en la generalidad de los casos produce y reproduce unas rutinas difíciles de remover por los hábitos y las condiciones de segu- 
Política de inclusión social en el gobierno de Chávez: una mirada a su proceso Rodríguez Colmenares, Isabel

ridad que generan, además que, la innovación no forma parte consustancial de las dinámicas burocráticas con las cuales ella se desempeña.

En la generalidad de las instituciones y organizaciones privadas y, más aún, en las públicas, el cambio se percibe como algo que interrumpe las rutinas a las que las personas que laboran en ellas están acostumbradas, por lo que tiende a experimentar una reacción contraria a que ello ocurra y a manifestar una oposición cerrada e irracional frente a cualquier propuesta de cambio. Los esquemas burocráticos de organizaciones por su parte son abiertamente reconocidos como resistentes al cambio (Rodríguez, 2000).

Rodríguez (2000: 217) señala una serie de factores que dan origen o son los responsables directos de la resistencia al cambio: Entre ellos destaca la necesidad de seguridad apelando a las características psicológicas que relacionan la preferencia por lo conocido antes que lo desconocido, tal cual estudios de Maslow, 1989 citado por Rodriguez (2000); la amenaza a los intereses; la falta de visión para evaluar posibles beneficios futuros; la inercia del funcionamiento de la estructura funcional y organizacional; la falta de recursos; la censura; la ausencia de proactividad y el miedo personal para disentir frente a la autoridad superior; entre otros rasgos que son muy validos en toda organización.

En el caso venezolano estas razones de una u otra forma han estado presentes en la administración pública existen factores de índole políticos, sobre los cuales no se han efectuado estudios psicopolíticos, sociopolíticos y politológicos y que forman parte consustancial a la cultura organizacional ${ }^{9}$ de la administración pública que están relacionados e imbricados con la actividad política y el perjuicio encubierto que se ha venido desarrollando de manera reiterada desde mucho tiempo en el aparato público y esas actividades han venido de forma virulenta alentada por los partidos políticos de manera soterrada. Así mismo, las críticas poco constructivas han abundado sin anteponer $u$ ofrecer soluciones alternativas plausibles.

\section{A manera de reflexión final}

Como el presente estudio se propuso adelantar un análisis de la política social de inclusión en el gobierno de Chávez, de manera exploratoria, se han podido establecer algunas conjeturas que servirán de pauta orientadora para el desarrollo de la propia investigación que continua. En el decurso de la historia de Venezuela se han vivido épocas intere-

9 Según Rodríguez (2000), el término cultura organizacional probablemente haya sido por primera vez empleado por Pettigrew, en 1979, pero su mayor difusión se le debe a Edgar Schein a partir de la publicación de su obra en la década del ochenta. Un estudio sobre la utilización de este concepto, impacto y evolución teórica en los distintos ámbitos en los cuales suele usarse, se encuentra en Vásquez (2008). 
santes, que han dado origen a cambios sustantivos en su acontecer. Las particularidades del momento actual constituyen una evidencia de ello, sobre todo cuando se ha hecho una recomposición analítica de las variables que dan cuenta de la implantación de la política socia de inclusión, abonando el terreno para una serie de planteamientos conclusivos que definan las acciones investigativas subsecuentes de este proyecto de investigación en curso.

Cuando se trata de implantar políticas de inclusión social, la complejidad se incrementa por la trama de intereses que se ven afectados. Para el caso venezolano, durante este gobierno esto ha quedado demostrado, pues no solamente se afectan intereses como ocurre con la implantación de cualquier política pública que supone, como se ha argumentado, un cierto grado de afectación a los intereses de otros actores o grupos sociales sino que aquí han intervenido otras variables asociadas al contexto político en que se ha registrado esta formulación e implantación por cuanto se trata de alterar la lógica de ocurrencia de dicho proceso. Pues a partir de ellas se persigue redefinir la relación Estado-sociedad.

De esta forma las tensiones no se quedaron en la dinámica del aparato público, sino que van a drenar hacia todo el sistema político y por ende a traspasar hacia la sociedad en su conjunto.

Esos intereses que se ven afectados guardan relación con la estructuración de relaciones de poder preexistentes. Al registrarse un cambio en la lógica de la relación Estado-sociedad se afecta la estructura de poder. Las cuotas de poder siempre tienden a ser preservadas recurriendo a cualquier mecanismo; al establecerse un cambio en términos de pasar de una democracia representativa a una democracia participativa, el poder se distribuye de manera más equitativa, permitiéndole a diversos sectores formar parte del engranaje de las políticas públicas sociales: entonces se producen diversos tipos de tensiones, obteniéndose la desigualdad en el impacto de las políticas públicas por las fricciones entre los actores.

Las concepciones valorativas bajo las cuales se formó el Estado democrático representativo, creó ilusiones de igualdad y de participación que resultan difíciles de ser demostradas, incluso para su comprensión por los propios afectados y desmontarlas en el aparato público por factores de constitución del propio aparato de Estado. Por tales razones, los desafíos que lleva implícito la adopción y avance de la política social de inclusión son de diverso tipo, entre las que destacan no solamente el componente político sino los factores de índole cultural, socio-educativa y axiológicos. De allí su elevado nivel de complejidad.

Por último, es importante considerar que la política social es compleja; y los análisis de los objetivos que se persiguen y las herramientas que se estructuran para lograrlos, en términos de inclusión social, siempre son limitados por la dinámica propia de la sociedad. Por tanto, nunca se dictamina la última palabra. 


\section{Referencias bibliográficas}

Abramovich, Victor (2006). “Una aproximación al enfoque de derechos en las estrategias y políticas de desarrollo". Revista de la Cepal. No. 88. Santiago de Chile, Chile. Pp. $35-50$

Alvarado, Neritza (2012). El modelo endógeno socialista en Venezuela y sus estrategias de inclusión social. Revista de Ciencias Sociales (RCS). Vol. XVIII. No. 4. Octubre - Diciembre 2012. Pp. $641-656$.

Arellano Gault, D. (1996). "Política pública, racionalidad imperfecta e irracionalidad. Hacia una perspectiva diferente". Gestión y política pública. Vol. 5 No. 2 Segundo Semestre. Pp. 319 - 347.

Asamblea Nacional Constituyente (1999). Constitución de la República Bolivariana de Venezuela. Imprenta Nacional. Caracas, Venezuela.

Arriagada, Irma (2006). "Cambios de las políticas sociales: políticas de género y familia". Serie Políticas Sociales. No. 119. Cepal, Santiago de Chile, Chile.

Ball M. Carlos (1992). "Venezuela: el triste caso de un gobierno rico y un país paupérrimo". En: Barry B. Levine. EI desafío neoliberal: El fin del tercer mundismo en América Latina. Editorial Norma. Buenos Aires, Argentina, pp. 283-306.

Banco Mundial (2000). Informe sobre el desarrollo mundial, 1999-2000. En el umbral del siglo XXI. Banco Mundial. Ediciones Mundi-Prensa. Madrid.

Barba Solano, Carlos (2009). "Los estudios sobre la pobreza en América Latina". Revista Mexicana de Sociología. No. 71. UNAM. México. pp. 9-49."

Bemeguy. A, Esther, Nader, Rosa María y Fereira. G, Angela, C. (2009). "El estado y la sociedad civil brasileña en el diálogo sobre el desarrollo nacional. Revista del Clad. Reforma y Democra- cia. No. 45. Caracas, Venezuela, pp. 137-204.

Comisión Económica para América Latina y el Caribe (1990). Transformación productiva con equidad. Naciones Unidas/Cepal. Santiago de Chile.

Congreso Nacional (1987). Ley Orgánica del Sistema Nacional de Salud, Gaceta Oficial No. 33.745, de fecha 23-061987. Imprenta Nacional. Caracas, Venezuela.

Congreso Nacional (1989). Ley Orgánica de Descentralización, Delimitación y Transferencias de Competencias al Poder Público, Gaceta Oficial No. 4.153, de fecha 28-12-89. Imprenta Nacional. Caracas, Venezuela.

Córdova, Edgar (2012). Los desafíos de la política comunitaria en Venezuela. Revista de Ciencias Sociales (RCS). Vol. XVIII. No. 4. Octubre - Diciembre 2012. Pp. 670 - 683.

D’Amario, Dalsy (2009). "Cuestiones de la inclusión educativa. A propósito de la UBV y la Misión Sucre". Revista Venezolana de Economía y Ciencias Sociales. Vol. 15. No. 1. UCV. Caracas, Venezuela. pp. 225-253.

D'Elia, Yolanda y Maingon, Thais (2010). La política social en el Modelo Estado/Gobierno venezolano. Ildis/Convite A.C. 13 pag.

Delgado Gutiérrez, Adriana (2002). "Las políticas sociales en la perspectiva de los derechos y la justicia". Ponencia presentada en resumen de expertos: "EI impacto de la reforma de pensiones en Colombia sobre la equidad de género". 31 de octubre. Bogotá.

De la Cruz, Rafael (1992). "La estrategia de la descentralización en Venezuela”. En Rafael de la Cruz (coordinador). Descentralización, Gobernabilidad y Democracia. COPRE-PNUD-Nueva Sociedad. Caracas, Venezuela. pp. 15-73. 
Díaz Polanco, Jorge y Borges, Sandra (2010). "La década bolivariana de salud: un secreto mal guardado". En: F. Ramos et al. Hugo Chávez: una década en el poder. Facultad de Ciencias Políticas y Gobierno y Relaciones Internacionales. Editorial Universitaria del Rosario. Bogotá, Colombia. pp. 387405.

Fleury, Sonia; Molina, Carlos "Modelos de protección social. BID/ Instituto Interamericano para el Desarrollo Social (Indes)" Diseno y Gerencia de Políticas y Programas Sociales.

Gil Yepez (1978). El reto de las élites. Editorial Tecnós. Madrid, España.

Guédez Víctor (1999). "La postmodernidad: mito real o realidad mitológica". Relea. No. 8. Cipost, UCV, Caracas. pp. 201-217.

Guevara, Pedro (1989). Concertación y conflicto. El pacto social y el fracaso de las respuestas consensuales a la crisis del sistema político venezolano. Facultad de Ciencias Jurídicas y Políticas. UCV. Caracas, Venezuela.

Gutiérrez, Thais (2011). Crítica epistémica a la política social en clave moderna. Revista Utopía y praxis latinoamericana. Ano 16. No. 54 (Julio - Septiembre). Pp. $117-125$

Isuani, Ernesto Aldo (2007). "Política social en la región: Desafíos políticos y de gestión". Revista del Clad. Reforma y Democracia. No. 38. Caracas, Venezuela. pp. 49-72.

Kesslen y Di Virgilio (2008). "La nueva pobreza urbana: dinámica global y regional". Revista de la Cepal. No. 95. Santiago de Chile. pp. 31-50.

Lahera, Eugenio (2004). Política y Políticas Públicas. Serie Políticas Sociales No. 95. Cepal, Santiago de Chile.
López Maya, Margarita (1998). "Problemas de los partidos populares en la transición (tras una alternativa política en Venezuela. En Contribuciones. No. 11998. Pp. 79 - 106.

Merino, Mauricio (2008). "La importancia de la ética en el análisis de las políticas públicas". Revista del Clad. Reforma y Democracia. No. 41. Caracas, Venezuela. pp. 5-32.

Moreno Brid, Juan Carlos; Pérez C., Esteban y Ruíz N., Pablo (2004). "El consenso de Washington: aciertos, yerros y omisiones". Revista Perfiles Latinoamericanos. Facultad Latinoamericana de Ciencias Sociales. No. 25. México. Pp. 149-167.

Moro, Javier (2009). "La información y el conocimiento en la gestión social: entre expectativas incumplidas y usos estratégicos". En: M. Chiara y M. Di Virgilio (Coord.) Gestión de la política social. Conceptos y Herramientas. Prometeo Libros. Buenos Aires, pp. 297-317.

Ocampo, José Antonio (2008). "Las concepciones de la política social: universalismo versus focalización. Revista Nueva Sociedad. No. 215. Mayo - Junio. Pp. 36-61.

Rodríguez, Dario (2000). Gestión organizacional: Elementos para su estudio. Ediciones Universidad Católica de Chile. Chile.

Vásquez, María del Carmen (2008). "Claves para una relectura de la cultura organizativa desde los paradigmas sociológicos". Espacio Abierto. Vol. 17. No. 1. LUZ. Venezuela. pp. 27-52.

Vivancos, Francisco y España, Luis Pedro (1993). La crisis que nos falta por recorrer: Perspectiva social de Venezuela 1992/2005. Ildis/Nueva Sociedad. Caracas, Venezuela. 